\title{
Palliative Gastrectomy versus Gastrojejunostomy for advanced Gastric cancer with outlet obstruction: a propensity score matching analysis
}

Xiao-Jiang Chen ${ }^{\dagger}$, Guo-Ming Chen ${ }^{\dagger}$, Yi-Cheng Wei ${ }^{\dagger}$, Hong Yu, Xi-Cheng Wang, Zhou-Kai Zhao, Tian-Qi Luo, Run-Cong Nie and Zhi-Wei Zhou*

\begin{abstract}
Background: Gastric outlet obstruction (GOO) is a late complication of advanced gastric cancer, and it is controversial how to select the therapeutic strategies: gastrojejunostomy and palliative gastrectomy? Therefore, this study was to compare the surgical and survival outcomes of gastrojejunostomy and palliative gastrectomy.

Methods: In total, 199 gastric cancer patients with outlet obstruction treated by surgery between January 2000 and December 2015 at Sun Yat-sen University Cancer Center were retrospectively reviewed. Patients were divided into gastrojejunostomy group and palliative gastrectomy group. Propensity score matching (PSM) was performed to balance the selection bias.

Results: After 1:1 PSM, a total of 104 patients were included for final analysis. The median overall survival (OS) times in the gastrojejunostomy group and palliative gastrectomy group were 8.50 and 11.87 months, respectively $(P=$ 0.243). The postoperative complication rates in the gastrojejunostomy group and palliative gastrectomy group were $19.23 \%(10 / 52)$ and $17.31 \%(9 / 52)$, respectively $(P=0.800)$, and no treatment-related death was observed. Multivariate analysis showed that periton0eal seeding $(P=0.014)$ and chemotherapy $(P<0.001)$ were independent prognostic factors. Among them, peritoneal seeding was a risk factor and postoperative chemotherapy was a protective factor.

Conclusions: Our results indicated that although the surgical complications of palliative gastrectomy were manageable, it showed no survival benefit. Therefore, relieving obstruction symptom, improving patients' quality of life and creating better conditions for chemotherapy appear to be the main therapeutic strategies for advanced gastric cancer with GOO.
\end{abstract}

Keywords: Advanced gastric cancer, Outlet obstruction, Gastrojejunostomy, Palliative gastrectomy, Overall survival

\footnotetext{
* Correspondence: nierc@sysucc.org.cn; zhouzhw@sysucc.org.cn

${ }^{+}$Xiao-Jiang Chen, Guo-Ming Chen and Yi-Cheng Wei contributed equally to this work.

Department of Gastric Surgery, Sun Yat-sen University Cancer Center, No.651 Dongfeng Road East, Guangzhou 510060, Guangdong, China
}

(c) The Author(s). 2021 Open Access This article is licensed under a Creative Commons Attribution 4.0 International License, which permits use, sharing, adaptation, distribution and reproduction in any medium or format, as long as you give appropriate credit to the original author(s) and the source, provide a link to the Creative Commons licence, and indicate if changes were made. The images or other third party material in this article are included in the article's Creative Commons licence, unless indicated otherwise in a credit line to the material. If material is not included in the article's Creative Commons licence and your intended use is not permitted by statutory regulation or exceeds the permitted use, you will need to obtain permission directly from the copyright holder. To view a copy of this licence, visit http://creativecommons.org/licenses/by/4.0/ The Creative Commons Public Domain Dedication waiver (http://creativecommons.org/publicdomain/zero/1.0/) applies to the data made available in this article, unless otherwise stated in a credit line to the data. 


\section{Introduction}

Gastric cancer is responsible for over 1,000,000 new cases and an estimated 783,000 deaths in 2018, making it the fifth most frequently diagnosed cancer and the third leading cause of cancer death [1]. Various therapeutic strategies, including surgery, chemotherapy, targeted therapy, immunotherapy, and radiation therapy, have been demonstrated to improve the overall survival (OS) times for advanced gastric cancer [2].

Unfortunately, more than $80 \%$ of gastric cancer patients in China are diagnosed with advanced stages at the first clinic visit [3]. Gastric outlet obstruction (GOO) is a late complication of advanced gastric cancer. It leads to vomiting, inability to tolerate oral intake, weight loss, malnutrition for patients, which deprives them of the opportunity for proper treatment $[4,5]$. Therefore, the treatment of GOO is of great importance for advanced gastric cancer with outlet obstruction.

There are currently three treatment options to alleviate GOO: endoscopic metallic stent insertion, gastrojejunostomy and palliative gastrectomy [5-7]. Among them, palliative gastrectomy is the radical therapeutic strategy that aimed to relieve the symptom and prolong the survival of the GOO patients. To date, few studies have evaluated the effect of palliative gastrectomy on those patients, the value of palliative surgical resection is still controversial. Although REGATTA trial demonstrated that the gastrectomy followed by chemotherapy could not show survival benefit compared with chemotherapy alone, its subgroup analysis indicated that the distal advanced gastric cancer may still benefit from gastrectomy [8]. Some previous retrospective studies have suggested that surgical resection may have a survival benefit $[6,9]$. However, Okumura Y et al. reported that palliative gastrectomy offers no survival benefit as compared to gastrojejunostomy [10]. Up to now, most of the current studies were retrospective and have selection bias among enrolled patients.

Therefore, using the propensity score matching method to balance the selection bias, the aim of this study was to compare the safety and the impact on the overall survival of gastrojejunostomy and palliative gastrectomy for advanced gastric cancer with outlet obstruction.

\section{Materials and methods \\ Patients}

Patients were eligible if they were histologically proven diagnoses of gastric adenocarcinoma and outlet obstruction in Sun Yat-sen University Cancer Center between January 2000 and December 2015. All patients enrolled in the study were treated with surgery, including gastrojejunostomy and palliative gastrectomy. The palliative gastrectomy was performed by open surgery to remove the primary tumor and two-thirds of the distal stomach without dissection of the lymph nodes.

\section{Data collection}

We reviewed the clinicopathologic characteristics before surgery and clinical outcomes after surgery of all patients. The characteristics included the age, gender, Eastern Cooperative Oncology Group performance score (ECOG PS), pre-procedure gastric outlet obstruction scoring system (GOOSS), baseline serum carcinoembryonic antigen (CEA), ascites, tumors around invasion of tissues and organs, degree of peritoneal seeding, distant organ metastasis, time of first oral eating after operation, average length of hospital stay, postoperative complications, postoperative chemotherapy, and overall survival. All the postoperative outcomes were enrolled in this study were occurred within 30 post-operative days.

GOOSS is defined as 0 for no oral intake, 1 for liquids only, 2 for soft solids, and 3 for low residue or full diet [11]. According to the first English edition of the Japanese classification of gastric carcinoma, the degree of peritoneal seeding ' is classified as follows: P0, no peritoneal seeding; P1, disseminating metastasis to the region directly adjacent to the peritoneum of the stomach (above the transverse colon, including the greater omentum); P2, several scattered metastases to the distant peritoneum and ovarian metastasis alone; P3, numerous metastases to the distant peritoneum [12];

All regular follow-up assessments were completed by June 2019, and the median follow-up time was 15.31 months (range, 1.62-102.00 months).

This study complied with the Declaration of Helsinki and was approved by the institutional review board of Sun Yat-sen University Cancer Center. Informed consent was obtained from all individual participants included in the study.

\section{Propensity score matching Agesnalysis}

The propensity score, defined as the conditional probability of receiving treatment, is commonly built in observational studies to adjust for selection bias $[13,14]$. Because patients were not randomly assigned to the gastrojejunostomy and palliative gastrectomy groups, propensity score matching was applied to control the selection bias. In this study, the 1:1 nearest neighbor matching were chosen for the propensity score. Propensity score matching was performed using IBM SPSS version 22.0 (IBM SPSS, Armonk, NY).

\section{Statistical analysis}

All of the statistical analyses were performed using the IBM SPSS version 22.0 (IBM SPSS, Armonk, NY). Chi square tests were used to compare categorical variables, 
and non-parametric tests were used to compare continuous variables. Univariate and multivariate analyses for survival were performed using Cox's regression analysis. Variables with a $p$ value $<0.05$ in the univariate analysis were entered into multivariate analysis using Cox proportional hazard regression models. The forward selection method was used for multivariate Cox proportional analysis. The hazard ratio (HR) and 95\% confidence interval (CI) were used to estimate the survival predictor.
The overall survival (OS) was calculated from the diagnosis of gastric outlet obstruction to death. KaplanMeier survival curves with log-rank testing were performed to compare the survival benefits. Two-sided $P$ values $<0.05$ were considered to be significant.

\section{Results}

Patient baseline characteristics

In this study, a total of 199 patients were included, with 89 patients in the gastrojejunostomy group and 110

Table 1 Clinicopathological characteristics of gastric cancer patients with outlet obstruction before and after propensity score matching

\begin{tabular}{|c|c|c|c|c|c|c|}
\hline \multirow[t]{2}{*}{ Characteristics } & \multicolumn{2}{|c|}{ Before propensity score matching } & \multirow{2}{*}{$\begin{array}{l}p \\
\text { value }\end{array}$} & \multicolumn{2}{|c|}{ After propensity score matching } & \multirow{2}{*}{$\begin{array}{l}p \\
\text { value }\end{array}$} \\
\hline & $\begin{array}{l}\text { Gastrojejunostomy } \\
\text { group (\%) }\end{array}$ & $\begin{array}{l}\text { Palliative } \\
\text { gastrectomy } \\
\text { group (\%) }\end{array}$ & & $\begin{array}{l}\text { Gastrojejunostomy } \\
\text { group (\%) }\end{array}$ & $\begin{array}{l}\text { Palliative } \\
\text { gastrectomy } \\
\text { group (\%) }\end{array}$ & \\
\hline No. of patients & 89 & 110 & & 52 & 52 & \\
\hline Age (years) & & & 0.701 & & & 0.694 \\
\hline$\leq 60$ & $51(57.3)$ & $66(60.0)$ & & 27(51.9) & $29(55.8)$ & \\
\hline$>60$ & $38(42.7)$ & $44(40.0)$ & & 25(48.1) & 23(44.2) & \\
\hline Gender & & & 0.171 & & & 0.083 \\
\hline Male & $67(75.3)$ & $73(66.4)$ & & $33(63.5)$ & $41(78.8)$ & \\
\hline Female & $22(24.7)$ & $37(33.6)$ & & 19(36.5) & $11(21.2)$ & \\
\hline $\begin{array}{l}\text { Body mass index } \\
\text { (mean, range) }\end{array}$ & $\begin{array}{l}21.0 \\
(13.1-31.9)\end{array}$ & $\begin{array}{l}20.4 \\
(14.2-31.4)\end{array}$ & 0.146 & $\begin{array}{l}21.1 \\
(15.6-28.5)\end{array}$ & $\begin{array}{l}20.1 \\
(14.2-27.3)\end{array}$ & 0.082 \\
\hline PS & & & 0.028 & & & 0.527 \\
\hline $0 / 1$ & $58(65.2)$ & $87(79.1)$ & & $34(65.4)$ & $37(71.2)$ & \\
\hline $2 / 3$ & $31(34.8)$ & 23(20.9) & & 18(34.6) & 15(28.8) & \\
\hline GOOSS & & & 0.325 & & & 0.823 \\
\hline 0 & $30(33.7)$ & $30(27.3)$ & & $13(25.0)$ & $14(26.9)$ & \\
\hline 1 & $59(66.3)$ & $80(72.7)$ & & 39(75.0) & $38(73.1)$ & \\
\hline $\begin{array}{l}\text { CEA (ng/ml, } \\
\text { mean, range) }\end{array}$ & $\begin{array}{l}3.1 \\
(0.1-615)\end{array}$ & $\begin{array}{l}2.4 \\
(0.2-275)\end{array}$ & 0.042 & $\begin{array}{l}4.3 \\
(0.6-612)\end{array}$ & $\begin{array}{l}2.3 \\
(0.2-194)\end{array}$ & 0.103 \\
\hline Ascites & & & 0.003 & & & 0.684 \\
\hline No & $50(56.2)$ & $84(76.4)$ & & $32(61.5)$ & $34(65.4)$ & \\
\hline Yes & $39(43.8)$ & $26(23.6)$ & & $20(38.5)$ & 18(34.6) & \\
\hline $\begin{array}{l}\text { Invasion of } \\
\text { adjacent organs }\end{array}$ & & & $<0.001$ & & & 1.000 \\
\hline No & $14(15.7)$ & $61(55.5)$ & & $14(26.9)$ & $14(26.9)$ & \\
\hline Yes & 75(84.3) & $49(44.5)$ & & $38(73.1)$ & $38(73.1)$ & \\
\hline Peritoneal seeding & & & 0.016 & & & 0.139 \\
\hline PO & $12(13.5)$ & $25(22.7)$ & & $7(13.5)$ & $9(17.3)$ & \\
\hline $\mathrm{P} 1 / 2$ & $32(35.9)$ & $51(46.4)$ & & $17(32.7)$ & $25(48.1)$ & \\
\hline P3 & $45(50.6)$ & $34(30.9)$ & & $28(53.8)$ & 18(34.6) & \\
\hline $\begin{array}{l}\text { Period of } \\
\text { chemotherapy }\end{array}$ & & & $<0.001$ & & & 0.095 \\
\hline 0 & $55(61.8)$ & $33(30.0)$ & & $27(51.9)$ & $21(40.4)$ & \\
\hline $1-4$ & 16(18.0) & $30(27.3)$ & & 10(19.2) & $20(38.5)$ & \\
\hline$\geq 5$ & $18(20.2)$ & $47(42.7)$ & & $15(28.9)$ & $11(21.1)$ & \\
\hline
\end{tabular}


patients in the palliative gastrectomy group. Table 1 shows the baseline characteristics of the 199 patients. As shown in Table 1, compared with patients in the palliative gastrectomy group, patients in the gastrojejunostomy group had poorer PS $(P=0.028)$, higher CEA $(P<0.042)$, more ascites $(P=0.003)$, more invasion of adjacent organs $(P<0.001)$, serious peritoneal seeding $(P=0.016)$, less periods of chemotherapy $(P<0.001)$, indicating the obvious selection biases between these two treatment strategies. Therefore, the covariates for propensity score matching were PS, CEA, ascites, invasion of adjacent organs, peritoneal seeding, periods of chemotherapy. After 1:1 PSM, the covariates were balanced, with both of 52 patients enrolled in the gastrojejunostomy group and palliative gastrectomy group, respectively (Table 1).

\section{Survival}

Before PSM, the median OS was 7.73 (95\%CI: 5.789.69) months in the gastrojejunostomy group and 15.93 (95\%CI: 10.94-20.93) months in the palliative gastrectomy group, the OS difference between two groups was significant $(P<0.001)$ (Fig. 1 a). Nonetheless, after PSM, the OS difference was not significant (median OS: 8.50 (95\%CI: 4.57-12.43) months vs 11.87 (95\%CI, 7.3716.36) month, $P=0.243$ ) (Fig. 1 b).

\section{Univariate and multivariate analysis}

After PSM, we examined prognostic factors for OS in all patients. In the univariate analysis, Gender (HR $(95 \% \mathrm{CI})$ : 0.627 (0.491-0.800), $P<0.001$ ), peritoneal seeding (HR (95\%CI): 2.830 (1.292-6.197), $P=0.020)$ and period of chemotherapy (HR (95\%CI): 0.263 (0.143-0.484), $P<$
0.001) were significant predictors of overall survival. Then, multivariate analysis demonstrated that only peritoneal seeding (HR (95\%CI): 3.308 (1.426-7.674), $P=0.014)$ and period of chemotherapy (HR $(95 \% \mathrm{CI})$ : $0.226(0.139-0.508), P<0.001)$ remained as prognostic factors (Table. 2).

\section{Postoperative outcomes}

Table. 3 shows postoperative surgical outcome data of these two procedures. In the gastrojejunostomy group, postoperative complications included three cases of abdominal bleeding, three cases of abdominal infection, two cases of pneumonia, one case of kidney failure and one case of stroke. In the palliative gastrectomy group, postoperative complications included two cases of abdominal bleeding, three cases of abdominal infection, two cases of incomplete ileus and two cases of pneumonia. The overall postoperative complication rates in the gastrojejunostomy group and palliative gastrectomy group were $19.23 \%(10 / 52)$ and $17.31 \%(9 / 52)$, respectively $(p=0.800)$, and no treatment-related death was observed in both groups $(p=1.000)$.

The time of first oral intake was $5.82 \pm 1.58$ days (95\%CI: 5.44-6.28 days) in the gastrojejunostomy group and $6.14 \pm 2.14$ days (95\%CI: $5.62-6.81$ days) in the palliative gastrectomy group, there was no significant difference in the time of first oral intake between the two groups $(P=0.405)$. However, the postoperative hospital stay was shorter in the gastrojejunostomy group than the palliative gastrectomy group (10.84 \pm 3.61 days (95\%CI: $9.77-11.83$ days) vs. $14.37 \pm 8.26$ days $(95 \%$ CI: 12.11-16.74 days), $P=0.007$ ). a

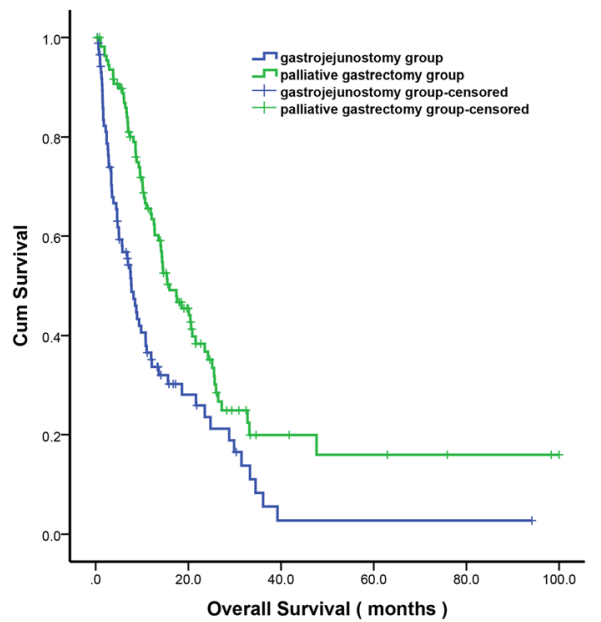

b

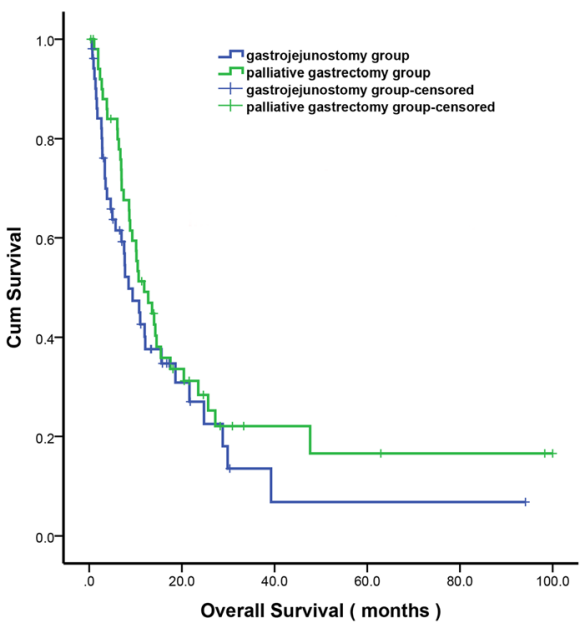

Fig. 1 Kaplan-Meier survival curves of the palliative gastrectomy and gastrojejunostomy groups for gastric cancer patients with outlet obstruction (a) before propensity score matching $(P<0.001)$ and $(\mathbf{b})$ after propensity score matching $(P=0.243)$. P-values were calculated using the log-rank test 
Table 2 Univariate and multivariate analysis of overall survival in gastric cancer patients with outlet obstruction after propensity score matching

\begin{tabular}{|c|c|c|c|c|}
\hline \multirow[t]{2}{*}{ Variables } & \multicolumn{2}{|l|}{ Univariate analysis } & \multicolumn{2}{|c|}{ Multivariate analysis } \\
\hline & HR (95\%Cl) & $P$ value & HR $(95 \% \mathrm{Cl})$ & $P$ value \\
\hline Age (years) & & 0.856 & & \\
\hline$\leq 60$ & 1 & & & \\
\hline$>60$ & $0.958(0.604-1.519)$ & & & \\
\hline Gender & & $<0.001$ & & 0.099 \\
\hline Male & 1 & & 1 & \\
\hline Female & $0.627(0.491-0.800)$ & & $0.646(0.384-1.086)$ & \\
\hline PS & & 0.057 & & \\
\hline $0 / 1$ & 1 & & & \\
\hline $2 / 3$ & $1.587(0.986-2.555)$ & 0.139 & & \\
\hline GOOSS & & 0.125 & & \\
\hline 0 & 1 & & & \\
\hline 1 & $0.661(0.389-1.122)$ & & & \\
\hline CEA & & 0.067 & & \\
\hline$<5 \mathrm{ng} / \mathrm{ml}$ & 1 & & & \\
\hline$\geq 5 \mathrm{ng} / \mathrm{ml}$ & 1.557 (0.969-2.503) & & & \\
\hline Ascites & & 0.122 & & \\
\hline No & 1 & & & \\
\hline Yes & $1.459(0.904-2.355)$ & & & \\
\hline Invasion of adjacent organs & & 0.181 & & \\
\hline No & 1 & & & \\
\hline Yes & $1.464(0.838-2.558)$ & & & \\
\hline Peritoneal seeding & & 0.020 & & 0.014 \\
\hline PO & 1 & & 1 & \\
\hline $\mathrm{P} 1 / 2$ & $1.781(0.816-3.884)$ & 0.147 & 2.087 (0.923-4.719) & 0.077 \\
\hline P3 & $2.830(1.292-6.197)$ & 0.009 & $3.308(1.426-7.674)$ & 0.005 \\
\hline Period of chemotherapy & & $<0.001$ & & $<0.001$ \\
\hline 0 & 1 & & 1 & \\
\hline $1-4$ & $0.464(0.269-0.803)$ & 0.006 & $0.405(0.226-0.727)$ & 0.002 \\
\hline$\geq 5$ & $0.263(0.143-0.484)$ & $<0.001$ & $0.226(0.139-0.508)$ & $<0.001$ \\
\hline Treatment & & 0.245 & & \\
\hline Gastrojejunostomy group & 1 & & & \\
\hline Palliative gastrectomy group & $1.315(0.829-2.084)$ & & & \\
\hline
\end{tabular}

$H R$ hazard ratio, $\mathrm{Cl}$ confidence interval

\section{Discussion}

Gastric cancer with outlet obstruction is a lifethreatening condition and usually associated with a dismal prognosis. Treatment selection was frequently done depending on the patient's condition and willing in the real clinical practice. In this study, we focused on the value of palliative surgical resection for advanced gastric cancer with outlet obstruction.

Recently, the value of palliative surgery for patients with gastric cancer has been evaluated in some prospective trials. The GYMSSA trial was aimed to compare palliative gastrectomy plus chemotherapy versus chemotherapy alone for patients with metastatic gastric cancer, but was closed prematurely due to poor participant accrual. Finally, only 17 patients were enrolled, therefore, it was difficult to draw any conclusions [15]. The REGATTA trial revealed that gastrectomy followed by chemotherapy did not show any survival benefit compared with chemotherapy alone in advanced gastric cancer with a single non-curable factor. However, its 
Table 3 Postoperative outcomes of gastric cancer patients with outlet obstruction

\begin{tabular}{|c|c|c|c|}
\hline & Gastrojejunostomy group $(n=52)$ & Palliative gastrectomy group $(n=52)$ & $P$ value \\
\hline \multicolumn{4}{|l|}{ Postoperative complications } \\
\hline Overall & 10 & 9 & 0.800 \\
\hline Abdominal bleeding & 3 & 2 & \\
\hline Abdominal infection & 3 & 3 & \\
\hline Incomplete ileus & 0 & 2 & \\
\hline Pneumonia & 2 & 2 & \\
\hline Kidney failure & 1 & 0 & \\
\hline Stroke & 1 & 0 & \\
\hline Time of first oral intake (days) ${ }^{a}$ & $5.82(4-11)$ & $6.14(4-15)$ & 0.405 \\
\hline Postoperative hospital stay (days) ${ }^{a}$ & $10.84(4-22)$ & $14.37(7-53)$ & 0.007 \\
\hline Hospital death & 0 & 0 & 1.000 \\
\hline
\end{tabular}

${ }^{a}$ Data are shown as mean (range)

subgroup analysis indicated that the distal advanced gastric cancer may still benefit from gastrectomy [8]. And most of the patients with GOO were distal advanced gastric cancer. Only a handful of retrospective studies have focused on this point. Keränen I et al. [6] compared three palliative methods to treat gastric outlet obstruction and found that palliative resection seems to provide a survival benefit in contrast with endoscopic stenting and gastrojejunostomy. In 2014, Okumura Y et al. [10] performed a retrospective analysis and showed that palliative distal gastrectomy offers no survival benefit as compared to gastrojejunostomy. However, the sample size was only 43 cases, indicating the low power to make this conclusion. These studies did not address risk adjustment; therefore, a selection bias may be present between palliative gastrectomy and gastrojejunostomy. In the present study, palliative gastrectomy was performed in better PS, lower CEA, less ascites, less invasion of adjacent organs and less peritoneal seeding patient. These patients had less tumor burden, more tolerance to chemotherapy and finally lead to better overall survival [16-20]. Consequently, the survival difference before PSM may be account for selection bias. After PSM, the obtained results revealed no significant differences in OS between these two therapies.

The present study demonstrated that the palliative gastrectomy or gastrojejunostomy was not an independent risk factor for survival in the multivariate analysis, whereas the peritoneal seeding and postoperative chemotherapy were independent prognostic factors for survival. Among the metastasis patterns of gastric cancer, peritoneal seeding is the most frequent pattern and cause of death in patients with gastric cancer [21]. In our study, $81.4 \%$ of patients were diagnosed with peritoneal seeding at the time of diagnosis. For gastric cancer patient with peritoneal seeding, several investigators have suggested that palliative gastrectomy should be recommended in selective P1 patients with peritoneal implantation [12, 20]. However, peritoneal seeding is often more severe in patients with GOO. In our study, 60.3\% patients suffered from P2/3 peritoneal implantation, no studies have been conducted to verify this in patients with GOO. At present, a lot of prospective studies have defined chemotherapy as a standard of care for stage IV gastric cancer [3, 22-24]. In the present study, after propensity score matching, the median OS of patients who underwent chemotherapy was significantly better than who not $(17.53 \mathrm{~m}$ versus. $6.13 \mathrm{~m} ; P<0.001)$ (Fig. 2), in agreement with other studies [25, 26].

In our study, the overall postoperative morbidity in the gastrojejunostomy group and palliative gastrectomy group were $19.23 \%(10 / 52)$ and $17.31 \%(9 / 52)$, respectively, and no treatment-related death was observed in patients who underwent palliative gastrectomy. Previous studies reported that the morbidity of palliative gastric resection ranged from 10.4 to $42 \%$ [12, 27, 28]. Hence, we considered that palliative gastrectomy was a safe procedure for patients with GOO. Nevertheless, the postoperative hospital stay was longer in the palliative gastrectomy group than the gastrojejunostomy group, which may lead to higher medical costs. As a whole, palliative gastrectomy cannot improve the prognosis, and the potential risk is theoretically high, therefore, the gastrojejunostomy is sufficient for patients with GOO.

There are some limitations in our study. First, this study is a retrospective study, and the data collection was in single center. Second, because of the rarity of gastric outlet obstruction due to gastric cancer, the study time span was over 15 years and many treatments are changing, especially in chemotherapy. Third, the quality of life after surgery is also an important concern for patients with GOO, but that was not been well evaluated in the present study. However, the number of patients enrolled in our study 


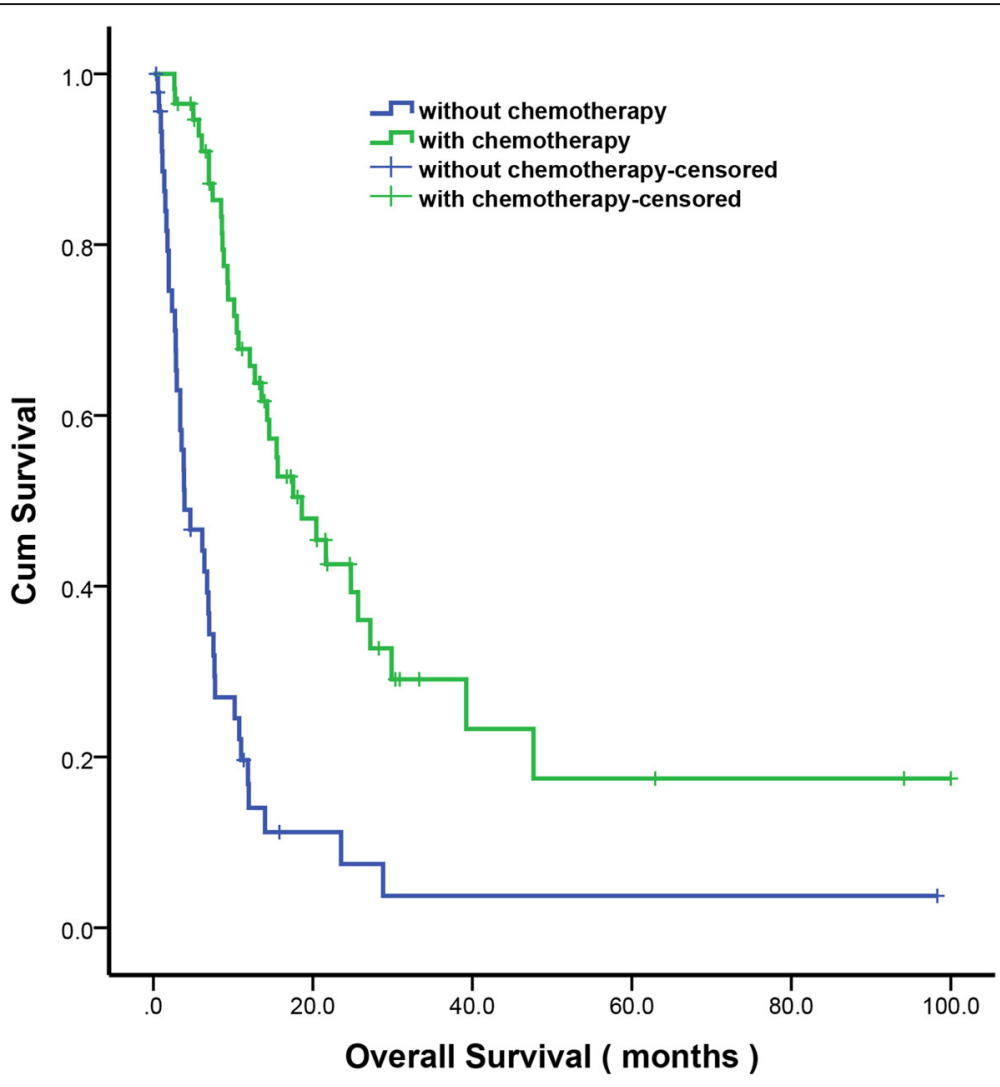

Fig. 2 Kaplan-Meier survival curves of gastric cancer patients with outlet obstruction according to chemotherapy after propensity score matching $(P<0.001)$. $P$-values were calculated using the log-rank test

was relatively large compared to previous studies. Additionally, we used propensity score matching to balance the selection bias and explore the value of palliative gastrectomy for advanced gastric cancer with outlet obstruction. In the future, prospective studies are needed to confirm the results.

\section{Conclusion}

The present study indicated that although the surgical complications of palliative gastrectomy were manageable, it showed no survival benefit. Therefore, relieving obstruction symptoms, improving patients' quality of life, and creating better conditions for chemotherapy appear to be the main therapeutic strategies for advanced gastric cancer patients with GOO.

\section{Abbreviations}

GOO: Gastric outlet obstruction; PSM: Propensity Score Matching Analysis;

OS: Overall survival; ECOG PS: Eastern Cooperative Oncology Group performance score; GOOSS: Gastric outlet obstruction scoring system; CEA: Carcinoembryonic antigen; Cl: Confidence intervals; HR: hazard ratio

\section{Funding statement}

This work was supported by the Chinese Society of Clinical Oncology Roche foundation grants: Y-2019Roche-157.

Authors' contributions

ZWW developed the concept of this work and lead the literature research and data collection. CXJ and NRC analyzed the data. CGM, YH, WXC, ZZK and LTQ contributed to the data collection and made the figures and tables. CXJ, CGM and WYC drafted the manuscript. All have read this final version and agreed to the submission.

\section{Availability of data and materials}

The data used to support the findings of this study are included within the article.

\section{Ethics approval and consent to participate}

This study complied with the Declaration of Helsinki and was approved by the institutional review board of Sun Yat-sen University Cancer Center. Informed consent was obtained from all individual participants included in the study.

Consent for publication

Not applicable.

Competing interests

The authors declare that there is no conflict of interests in this study. 
Received: 20 December 2020 Accepted: 8 February 2021

Published online: 23 February 2021

\section{References}

1. Bray F, Ferlay J, Soerjomataram I, Siegel RL, Torre LA, Jemal A. Global cancer statistics 2018: GLOBOCAN estimates of incidence and mortality worldwide for 36 cancers in 185 countries. CA Cancer J Clin. 2018;68:394-424.

2. Harada K, Lopez A, Shanbhag N, Badgwell B, Baba H, Ajani J. Recent advances in the management of gastric adenocarcinoma patients. F1000Research. 2018;7.

3. Wang FH, Shen L, Li J, Zhou ZW, Liang H, Zhang XT, Tang L, Xin Y, Jin J, Zhang YJ, Yuan XL, Liu TS, Li GX, Wu Q, Xu HM, Ji JF, Li YF, Wang X, Yu S, Liu H, Guan WL, Xu RH. The Chinese Society of Clinical Oncology (CSCO): clinical guidelines for the diagnosis and treatment of gastric cancer. Cancer communications. 2019;39:10.

4. Oh SY, Edwards A, Mandelson M, Ross A, Irani S, Larsen M, Gan SI, Gluck M, Picozzi V, Helton S, Kozarek RA. Survival and clinical outcome after endoscopic duodenal stent placement for malignant gastric outlet obstruction: comparison of pancreatic cancer and nonpancreatic cancer. Gastrointest Endosc. 2015;82(460-468):e462.

5. Jang SH, Lee H, Min B-H, Kim SM, Kim HS, Carriere KC, Min YW, Lee JH, Kim JJ. Palliative gastrojejunostomy versus endoscopic stent placement for gastric outlet obstruction in patients with unresectable gastric cancer: a propensity score-matched analysis. Surg Endosc. 2017;31:4217-23.

6. Keränen I, Kylänpää L, Udd M, Louhimo J, Lepistö A, Halttunen J, Kokkola A. Gastric outlet obstruction in gastric cancer: a comparison of three palliative methods. J Surg Oncol. 2013;108:537-41.

7. Haga Y, Hiki N, Kinoshita T, Ojima T, Nabeya Y, Kuwabara S, Seto Y, Yajima K, Takeuchi H, Yoshid K, Kodera Y, Fujiwara Y, Baba H. Treatment option of endoscopic stent insertion or gastrojejunostomy for gastric outlet obstruction due to gastric cancer: a propensity score-matched analysis. Gastric cancer. 2020.

8. Fujitani K, Yang HK, Mizusawa J, Kim YW, Terashima M, Han SU, Iwasaki Y, Hyung WJ, Takagane A, Park DJ, Yoshikawa T, Hahn S, Nakamura K, Park CH, Kurokawa Y, Bang YJ, Park BJ, Sasako M, Tsujinaka T. Gastrectomy plus chemotherapy versus chemotherapy alone for advanced gastric cancer with a single non-curable factor (REGATTA): a phase 3, randomised controlled trial. The Lancet Oncology. 2016;17:309-18.

9. Samarasam I, et al. Palliative gastrectomy in advanced gastric cancer: is it worthwhile? ANZ J Surg. 2006;76:60-3.

10. Okumura Y, Yamashita H, Aikou S, Yagi K, Yamagata Y, Nishida M, Mori K, Nomura S, Kitayama J, Watanabe T, Seto Y. Palliative distal gastrectomy offers no survival benefit over gastrojejunostomy for gastric cancer with outlet obstruction: retrospective analysis of an 11-year experience. World J Surg Oncol. 2014;12:364.

11. Adler DG, et al. Endoscopic palliation of malignant gastric outlet obstruction using self-expanding metal stents: experience in 36 patients. Am J Gastroenterol. 2002;97:72-8.

12. Nie RC, et al. Significant role of palliative Gastrectomy in selective gastric Cancer patients with peritoneal dissemination: A propensity score matching analysis. Ann Surg Oncol. 2016;23:3956-63.

13. Joffe MM, Rosenbaum PR. Invited commentary: propensity scores. Am J Epidemiol. 1999;150:327-33.

14. Garrido MM, et al. Methods for constructing and assessing propensity scores. Health Serv Res. 2014;49:1701-20.

15. Rudloff U, Langan RC, Mullinax JE, Beane JD, Steinberg SM, Beresnev T, Webb CC, Walker M, Toomey MA, Schrump D, Pandalai P, Stojadinovic A, Avital I. Impact of maximal cytoreductive surgery plus regional heated intraperitoneal chemotherapy (HIPEC) on outcome of patients with peritoneal carcinomatosis of gastric origin: results of the GYMSSA trial. J Surg Oncol. 2014;1 10:275-84.

16. Demirelli B, Babacan NA, Ercelep Ö, Öztürk MA, Kaya S, Tanrıkulu E, Khalil S, Hasanov R, Alan Ö, Telli TA, Koca S, Aribal ME, Kuzan B, Dane F, Yumuk PF. Modified Glasgow Prognostic Score, Prognostic Nutritional Index and ECOG Performance Score Predicts Survival Better than Sarcopenia, Cachexia and Some Inflammatory Indices in Metastatic Gastric Cancer. Nutrition and cancer. 2020:1-9.

17. Kochi M, et al. Evaluation of serum CEA and CA19-9 levels as prognostic factors in patients with gastric cancer. Gastric cancer. 2000;3:177-86.
18. Jung M, Jeung HC, Lee SS, Park JY, Hong S, Lee SH, Noh SH, Chung HC, Rha SY. The clinical significance of ascitic fluid CEA in advanced gastric cancer with ascites. J Cancer Res Clin Oncol. 2010;136:517-26.

19. Isozaki H, Tanaka N, Tanigawa N, Okajima K. Prognostic factors in patients with advanced gastric cancer with macroscopic invasion to adjacent organs treated with radical surgery. Gastric cancer. 2000:3:202-10.

20. Yuan S-Q, Nie R-C, Chen S, Chen X-J, Chen Y-M, Xu L-P, Yang L-F, Zhou Z-W Peng J-S, Chen Y-B. Selective gastric Cancer patients with peritoneal seeding benefit from Gastrectomy after palliative chemotherapy: A propensity score matching analysis. J Cancer. 2017;8:2231-7.

21. Hioki $\mathrm{M}$, et al. Predictive factors improving survival after gastrectomy in gastric cancer patients with peritoneal carcinomatosis. World J Surg. 2010; 34:555-62.

22. Glimelius B, et al. Randomized comparison between chemotherapy plus best supportive care with best supportive care in advanced gastric cancer. Ann Oncol. 1997;8(2):163-8.

23. Yun J, et al. A randomised phase II study of combination chemotherapy with epirubicin, cisplatin and capecitabine (ECX) or cisplatin and capecitabine (CX) in advanced gastric cancer. Eur J Cancer. 2010;46(5):88591.

24. Oba K, Paoletti X, Bang YJ, Bleiberg H, et al. Role of chemotherapy for advanced/recurrent gastric cancer: an individual-patient-data meta-analysis. Eur J Cancer (Oxford, England: 1990). 2013;49:1565-77.

25. Kim CG, et al. Effect of chemotherapy on the outcome of self-expandable metallic stents in gastric cancer patients with malignant outlet obstruction. Endoscopy. 2012:44:807-12.

26. Okumura Y, et al. Gastrojejunostomy followed by induction chemotherapy for incurable gastric cancer with outlet obstruction. World J Gastroenterol. 2010;16:4367-70.

27. Takeno A, Takiguchi S, Fujita J, Tamura S, Imamura H, Fujitani K, Matsuyama J, Mori M, Doki Y. Clinical outcome and indications for palliative gastrojejunostomy in unresectable advanced gastric cancer: multiinstitutional retrospective analysis. Ann Surg Oncol. 2013;20:3527-33.

28. Tokunaga M, Makuuchi R, Miki Y, Tanizawa Y, Bando E, Kawamura T, Terashima M. Surgical and survival outcome following truly palliative Gastrectomy in patients with incurable gastric Cancer. World J Surg. 2016; 40:1172-7.

\section{Publisher's Note}

Springer Nature remains neutral with regard to jurisdictional claims in published maps and institutional affiliations.

Ready to submit your research? Choose BMC and benefit from:

- fast, convenient online submission

- thorough peer review by experienced researchers in your field

- rapid publication on acceptance

- support for research data, including large and complex data types

- gold Open Access which fosters wider collaboration and increased citations

- maximum visibility for your research: over $100 \mathrm{M}$ website views per year

At BMC, research is always in progress.

Learn more biomedcentral.com/submissions 